\title{
Cooperation Development Prospects of the Primorsky Krai and China in the Humanitarian Sphere
}

\author{
Natalya Stepanovna Martyshenko \\ Department of International Marketing and Commerce \\ Vladivostok State University of Economics and Service \\ Vladivostok, Russia \\ natalya.martyshenko@vvsu.ru
}

\begin{abstract}
Humanitarian cooperation is an essential element of "soft power". Nowadays "soft power" tools acquire new content, improve cross-country cooperation in the economic sphere, form unifying political institutions and communications. Unlike Russia, China uses "soft power" tools more efficient. Recently China has been using particularly active "soft power" tools for promoting its global project "One Belt - One Road". Today by popularity the Chinese language has become the second studied language after English. The article discloses the problem of humanitarian cooperation between Russia and China by example of the Primorsky krai. It reveals particular features in formation and development of the popular diplomacy in relations between population of the Primorsky krai and border regions of China. The mechanism of "soft power" promoting cooperation has been researched by results from mass online surveys of the Primorsky krai residents. The survey focused on the problem of studying the mutual perception of Russians and Chinese. Such important resources of the "soft" power are disclosed as culture and education. Taking into account the multiplication of tourists from China to the Primorsky krai in recent years, the work deals with the development of cooperation between two countries in tourism sector. For the first time the research of relationship between two nations raises the problem of attitudes towards mixed marriages. The work develops the idea of measuring "soft power" characteristics. The proposed approach is based on using qualitative characteristics to measure "soft power" elements. There are examples of possible new solutions to use this mechanism.
\end{abstract}

Keywords: humanitarian cooperation, "soft power", public diplomacy, questionnaire survey, typological analysis

\section{INTRODUCTION}

In recent years the Russian - Chinese relations have been developed most dynamically. China is the largest trading partner of Russia. In 2018 the turnover reached 108 billion dollars. By 2024 it is planned to increase the turnover up to 200 billion dollars. Between the countries there are more than 300 intergovernmental agreements that cover practically all cooperation spheres. Long-terms projects include implementation of projects in the oil and gas sphere [1], cooperation in realization of the project "One Belt - One Road" [2].

For the Far East the increased cooperation and developed partnership between two countries have a special importance. Year after year the Chinese business is increasing the investment amount in the Far East region [3]. From all countries of the Asia-Pacific region the highest share of investments in the Far East is made by China.

In 2019 as part of cooperation between Russia and China during the Eastern Economic Forum - 2019 the agreements were signed for 852 billion rubles. According to the Federal Customs service the foreign trade between the Far East federal area with China for the period from January till June 2019 made 4,9 billion dollars ( $116 \%$ compared to the same period in 2018).

Developed cooperation between the countries has a positive impact on perception of each other by the citizens of both countries. Friendly relations of Russians towards China are proved by the survey results conducted by the "Public opinion" foundation in 2017 in 104 Russian settlements. Most surveyed people $(62 \%)$ consider China the most important and valuable partner for Russia. The survey of Chinese citizens in 2018 by the information service "Russia - China" proved that 93,6\% respondents in China positively assessed the current Chinese-Russian relations and $84,6 \%$ are optimistic about the "United destiny community" of two countries. "Forever friends" concept has rooted in Russia and China mainly due to improvement of bilateral humanitarian relations.

Significant results in cooperation in the humanitarian sphere were reached in the educational sphere [4, 5]. Generally, in the sphere of education there are about 950 cooperation agreements covering more than 150 Russian educational institutions and 600 Chinese. In 2017-2018 academic year in 305 higher schools from 85 Russian cities there were 30 thousand Chinese students. At the state level it was decided to increase the number of students by exchange up to 100 thousand in the near future. In Russia there is a systematic work to support the study of Russian language in 
In most stated publications the "soft power" is China. The work [6] examines the current trends and prospects of learning the Russian language in China. In Russia there is also the growing interest to learning the Chinese language [7]. In 2019 the Russian schoolchildren for the first time passed the Uniform state exam in Chinese.

Thanks to activities aimed at popularizing the culture of two countries, there is the increased tourist attraction for people of China and Russia [8]. In 2018 the tourist flow from Russia to China exceeded 2 million people. During the year the flow of tourists from China to Russia increased by $21 \%$ and also made over 2 million people. Primorsky krai takes leading positions on visiting by Chinese tourists. In 2018 Primorsky krai was visited by 422 thousand Chinese citizens, from them 365,5 thousand - for tourist purposes.

Due to the high importance of cooperation in the humanitarian sphere between Russia and China the study aimed at researching its problems is very relevant. For border regions such as Primorsky krai the humanitarian cooperation has a particular importance.

\section{LITERARY REVIEW AND RESEARCH METHODS}

A new stage in development of relations between Russia and China has come relatively recently. Not so long ago our countries were in a very difficult relationship and it was not easy to overcome it in a short period of time. Therefore, among deterring factors to develop the cross-border cooperation it is possible to identify firstly the lack of proper trust between entrepreneurs of China and Russia $[9,10]$.

One of the problems actively worked out in scientific publications is the problems related to studying mutual perception of Russian and Chinese [11]. For instance, in the work [12] it is stressed that one of the obstacles to the mutual understanding between representatives of two countries is the cultural specifics of two countries. Among other deterring factors of cooperation between business-structures it is possible to note the specifics of mentality and business doing in China.

Intercultural interaction also affects cooperation within the business community. To develop the cross-border cooperation it is needed to develop all communications between population of neighboring regions, as in the process of communication the image of the territory is formed. The work [13] considers the factors affecting the process to percept the "foreign" culture and to form the image of the territory. The most important tool to overcome the obstacles of mutual understanding is the "people's diplomacy" [14, 15].

China is one of the countries actively engaged in the "people's diplomacy". In China there is the increasing number of public organizations that find the public financial support [16]. The people's diplomacy is the "soft power" tool. Most Russian authors of scientific works believe that in Russia for many years the role of "soft power" has been underestimated $[17,18,19]$. Unlike Russia, China uses more efficiently the "soft power" tool [20, 21, 22]. Recently China has been using particularly active the "soft power" tools to promote its global project "One Belt - One Road" [23, 24]. characterized by certain qualitative features in different formats. The exemplary publications which attempt to develop the approaches to the use of quantitative characteristics for measuring the "soft power" elements, the following works can be named $[25,26]$.

This article develops the idea of measuring the "soft power" characteristics. The research was made in territory of the Primorsky krai. The population of the region and the territory bordering China more than people of other Russian regions, is concerned about the problem of establishing relations with this country.

To analyze the situation on the mutual trust of people from neighboring regions in two countries the residents of Primorsky krai were surveyed online. For the survey the special Google-form was developed and used that included 26 questions. Total of 1708 respondents took part in the survey. The data was processed with using EXCEL. But for standard tool specialized programs were used to process quality information.

\section{RESULTS}

In recent years Russia has started cooperation with AsiaPacific countries and especially China as one of the leaders in the region. Therefore it is interesting to know the regional population views of the decision to develop cooperation with China. Assessment of the population views was based on the analyzed answers of the respondents to the question: "What do you think is more important for Russia now: to improve economic and political relations with Western countries or China?" Results of the analyzed answers are given in Fig. 1. According to residents of the regions, cooperation with China is more improtant for Russia now than with Western countries (19\% vs $12 \%)$.

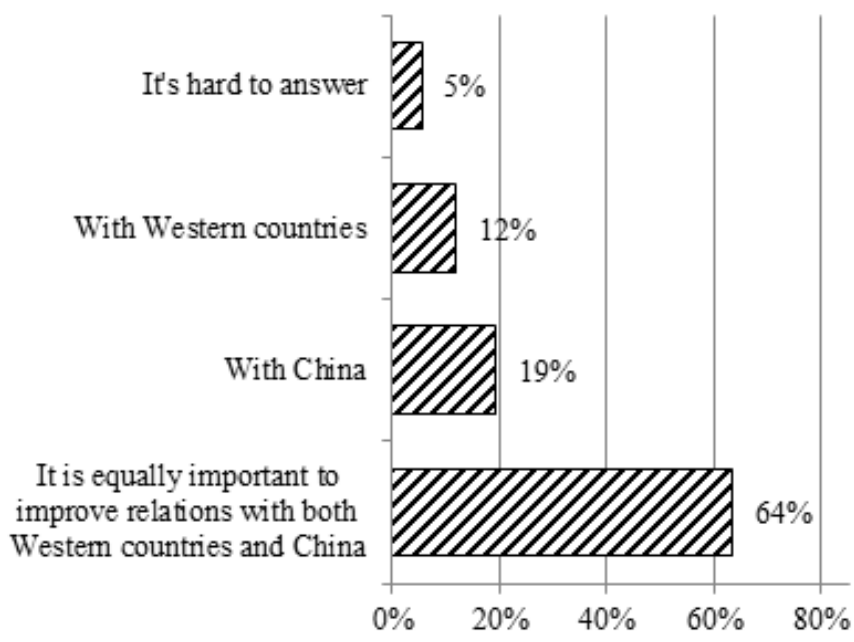

Fig. 1. Assement of the people attitude towads the governmental policy with orientation to China

Russia and China have a complex history of relations. Therefore, in the questionnaire the respondents were offered to express their attitude towards some statements that exist in the society: 
- China is saving us from the aggressive policy of the United States. But for the Chinese economic power, the United States would make us "much trouble";

- China is a military threat for Russia and it plans to seize our territories;

- China is an economic threat for us. It will push us out of the markets for Central Asian countries;

- Developed economic cooperation of Russia and China is very beneficial for development of the Russian Far East;

- China - is a strategic partner of Russia for the longterm prospect and it is needed to cooperate with China in all spheres.

Frequency rows of the level consent to these statements are given in Fig. 2.

Many respondents (31\%) fully support the strategic partnership expansion between two countries (statement 5). Only 5\% residents believe that China is an economic threat for Russia and 4\% - that China is a military threat. But only $4 \%$ hope that China can save Russia from the aggressive policy of the United States.

With quite large mutual flows of tourists there is surely active communication of residents in the countries. Most adult population of the Primorsky krai at least once visited China. Communication with Chinese citizens also takes place during their visit of the Primorsky krai. About 50\% respondents said that they had to communicate with Chinese people in their city, $26 \%$ communicated repeatedly and $24 \%$ had no contacts with Chinese citizens in their city. During communication people form their own opinion about representatives of other nation.

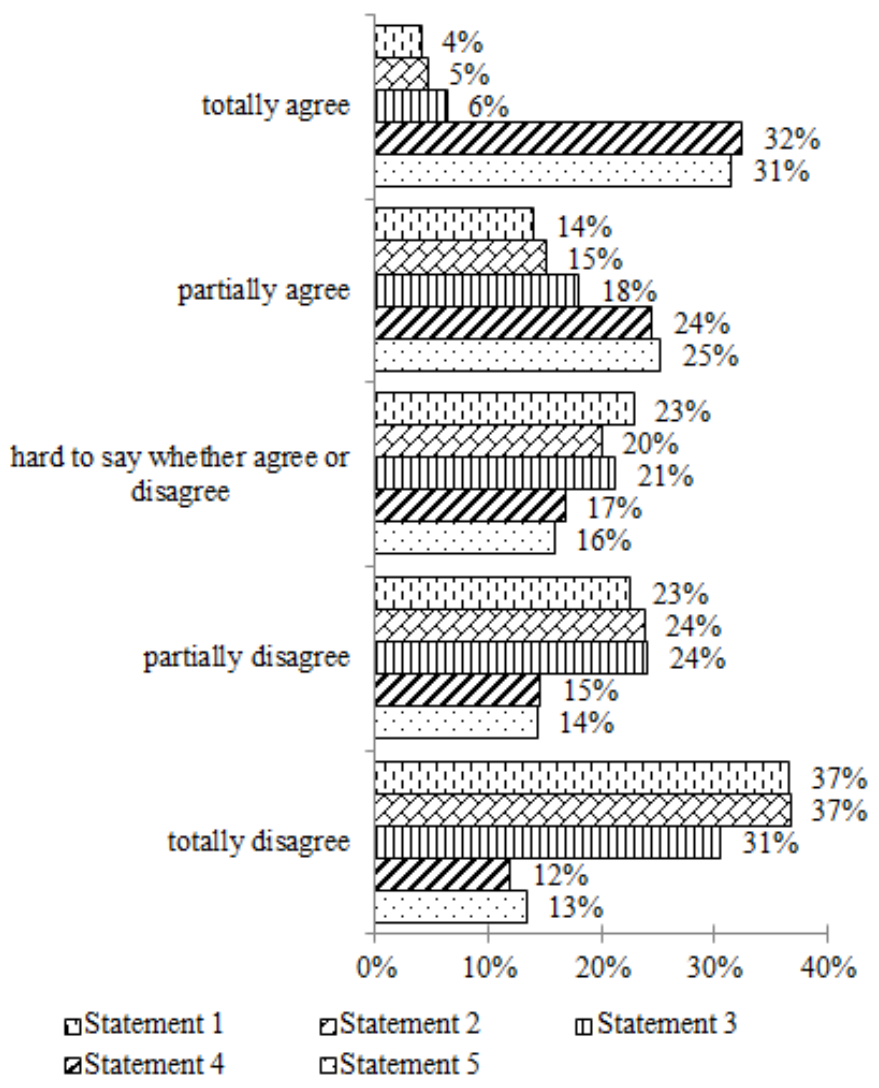

Fig. 2. Assessment of the attitude of the Primorsky krai population to possible prospects of the Russian - Chinese cooperation development, \% to the number of respondents

To assess the current impressions of the communication the following question of the questionnaire was used: "How do you assess the attitude of most common people in China to the population of Russia?" Most residents of the regions during communication with the Chinese formed the impression of friendly attitude to the Russian citizens (Fig. 3). However, other opinions can't be ignored. Other views prove that there is still mistrust of two nations, which still have a long way to go.

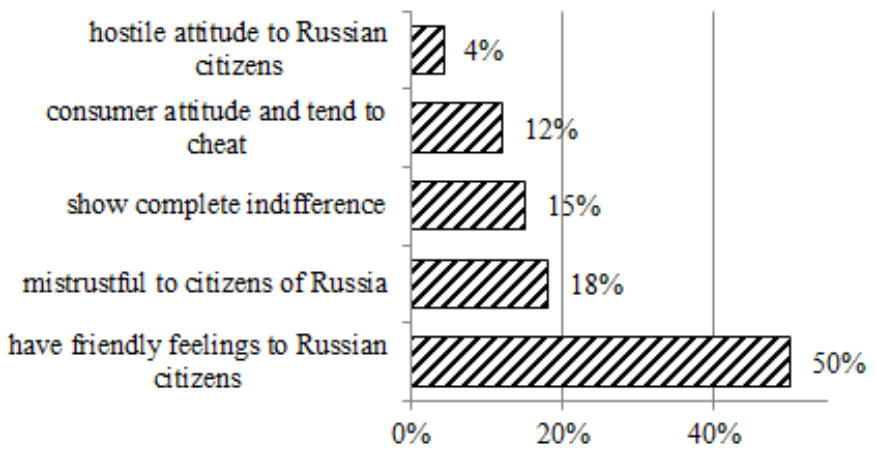

Fig. 3. Distributed assessed perception of the Chinese attitude to citizens of Russia by the people in the Primorsky krai

In recent years the flow of tourists to the Primorsky krai has increased in several times. At such a large flow of tourists 
- "What do you think about introduction in the

there are cases of negative attitudes affecting adversely the relationship of our peoples. There are some problems to be decided. But mostly residents of the region are positive towards Chinese tourists. It is proved by answers to the question: "What do you think of the growing tourist flow from China to the Primorsky krai?" The negative attitude to the growing flow of tourists from China is expressed by about $20 \%$ respondents (Fig. 4).

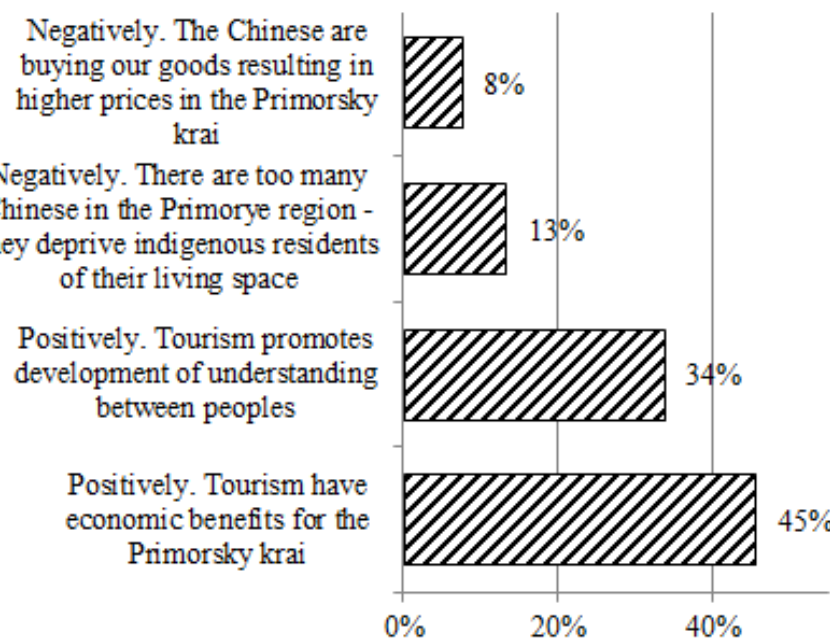

Fig. 4. Distributed assessed perception of the growing tourist flow from China by people in the Primorye Primorsky krai

With the growing economic cooperation, the Chinese citizen come to the Primorsky krai both for the tourism and business purposes. During their staying the country the Chinese citizens can enter not only in the business relations but also establish personal relations. Between the nations there might be racial bias. To assess racial bias in the questionnaire the following question was used: "What do you think of the mixed marriages of Russian and Chinese people (state one answer)?" Answers to this question proved a very high tolerance for the Chinese nation. Only 19\% respondents disapprove of mixed marriages (Fig. 5).

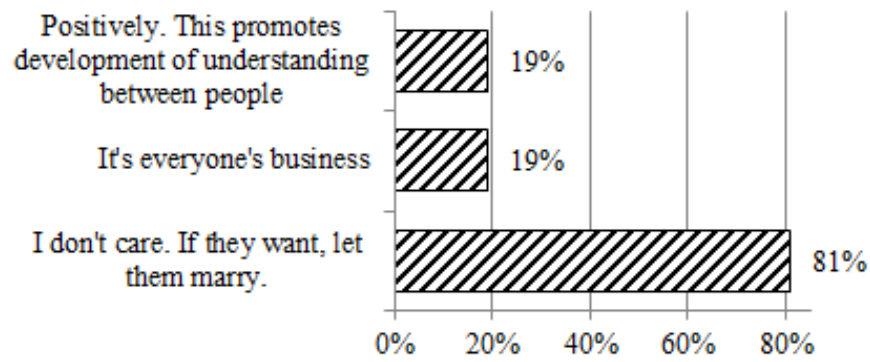

Fig. 5. Distributed assessed perception of mixed marriages by people in the Primorsky krai

Mostly the nations become closer through their desire to study the culture and language of other country. To assess the Primorsky krai interest in a deeper comprehension of the nearest neighbor the questionnaire included the following two questions: educational institutions for the obligatory program the study of history and culture of the neighboring countries (China, Korea, Japan)?";

- "In many countries in educational institutions there is not one foreign language to learn, but two. The second language - is the language of neighboring countries. What do you think of the second language to be Chinese (state one answer)?".

Analyzed results of the answers given by people in the Primorsky krai proves that most people perceives positively the deeper learning of culture in the neighboring countries (Fig. 6, Fig. 7). Only about a quarter of respondents think that to learn the culture and language of neighboring countries is needed only within the profile training programs.

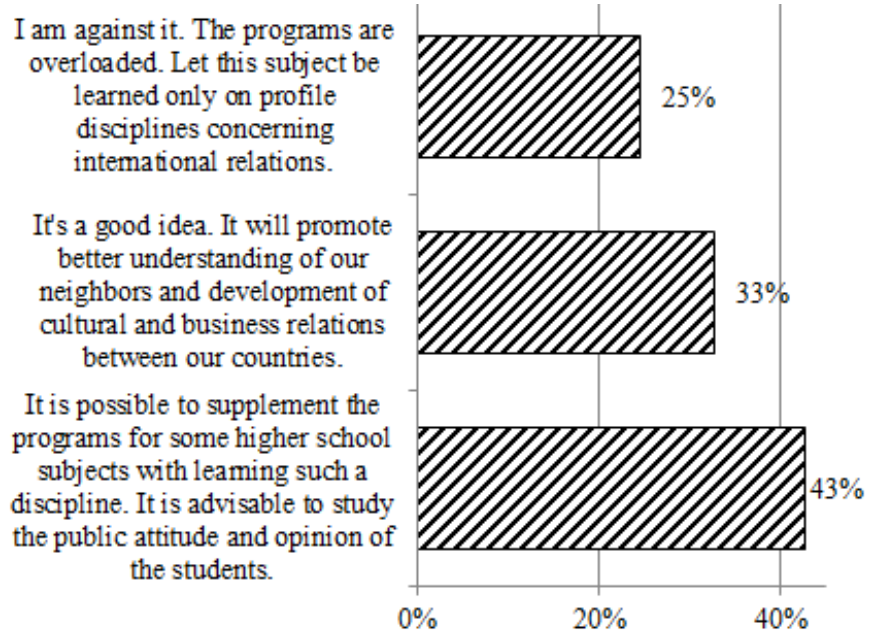

Fig. 6. Distributed assessed perception of the deeper learning of culture in the neighboring countries by people in the Primorsky krai

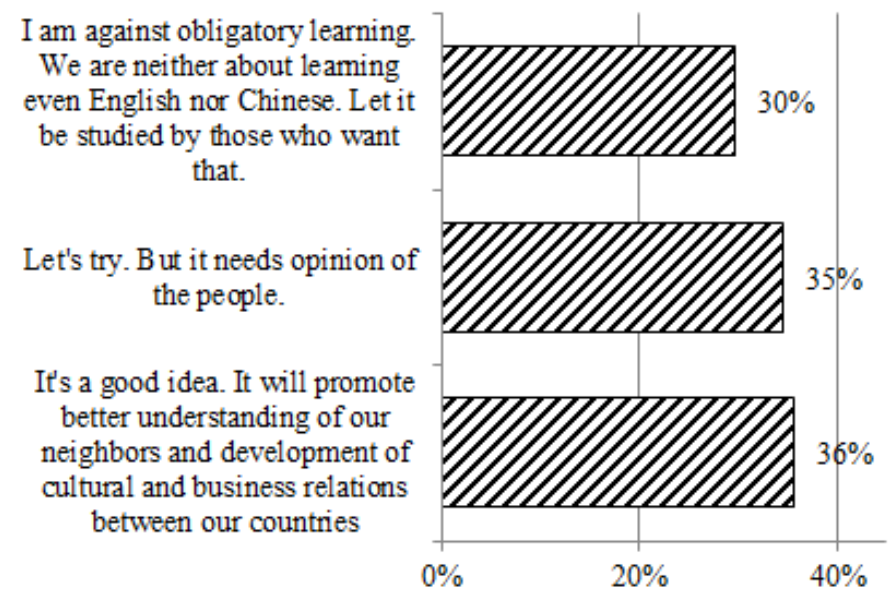

Fig. 7. Distributed assessed perception of attitude towards learning the language of neighboring countries by people in the Primorsky krai

\section{DISCUSSION}

At the time when the United State and its allies are pursuing an aggressive policy, "the soft power" becomes an 
essential tool for Russia to resist such a policy. To improve efficiency of the "soft power" in the Far East region systematic researches are needed as well as the state support of such researches. Although recently there have been more and more publications to the role and importance of using the "soft power" mechanisms, it is difficult to discover in them new proposals and ideas to be discussed. In this case we act as a catch-up, and catching up is always more expensive.

For the Primorsky krai the development of the crossborder cooperation with China has large prospects. At this stage the most important factor to develop cooperation is to increase the level of mutual trust. The made researches proved that for recent years the attitude of population in the region towards China has changed for the better. However, at the present stage it is needed to develop the contacts, especially in the business sphere and scientific environment.

Currently the information space for intercultural communications of China and Russia are only being formed. Distribution of information about the ongoing changes in the cultural and economic spheres of the Primorsky krai through Internet becomes more and more perspective. Due to the significant increase in the number of Chinese tourists it is needed to pay a special attention to formation of the favorable environment for such visits. It is required to enlarge the number of leaflets with description of cultural objects in Vladivostok in the Chinese language. Programs in the city theaters, menus in the central restaurants and cafes are preferably to be duplicated in Chinese.

The sphere of education as the most important "soft power" tool demands new approaches. In universities of the Fast East there is one third of Chinese students learning in Russia. At present in the Primorsky krai there are about 4 thousand foreign students, most of them are citizens of China. Most students have poor initial training and low motivation to study. After graduating from the university, the Chinese students generally do not work on profession [27]. The poor quality of training for the foreign students affect negatively the image of Russian education. On a budgetary basis it is needed to accept foreign students by competition. It is required to develop the training of students in high technological spheres. To improve cooperation between the countries it is needed to provide employment of the best foreign students in territory of the Russian Federation and simplify the procedure of obtaining the Russian citizenship for them. For that it is reasonable to use the experience of the United States. For instance, in the United States from 2004 to 2017 1,5 million highly qualified young specialists were employed from the number of foreign students in high-tech spheres of science, technologies, engineering and mathematics.

\section{CONCLUSION}

At present it is needed to encourage contacts of population in the border regions at the non-governmental level. Further expansion of contacts and mutual understanding between the peoples in Russia and China can be promoted by the joint participation in various landmark events, organized in the border territories. Therefore, it is important for the Primorsky krai now to form and develop the event-strategy in tourism. It is required to assist the expansion of the impact from the Russian orthodox church in the region. It is possible to consider the opening in Vladivostok a Christian seminary aimed at training of foreign citizens.

The problem of "soft power" should become a priority direction in the policy of Russia. For that we must not forget formation of the public opinion within the country. Without support of new initiatives inside the country the "soft power" policy will not result in the necessary effect.

The work develops the idea of measuring "soft power" characteristics. Such important resources of the "soft" power are disclosed as culture and education. For the first time the research of relationship between two nations raises the problem of attitudes towards mixed marriages. The proposed approach is based on using qualitative characteristics to measure "soft power" elements.

\section{REFERENCES}

[1] N. S. Martyshenko and A. D. Kletskin, "Development of cooperation between Russia and China and in the oil sector and its impact on the economy of the Primorsky krai", Bulletin of the Nizhny Novgorod State Engineering Economic University, 2019, 7 (98), pp. 88-99.

[2] L. V. Ponomarenko, "China's "One Belt One Road" Initiative As a method of connecting China with the world", Proceedings of the 2nd International Conference on Contemporary Education, Social Sciences and Humanities, ICCESSH 2017, Atlantis Press, 2017, vol. 124, pp. 1100-1103.

[3] D. V. Bunkovsky, et al., "Foreign investments and economic security of Russia", Actual problems of humanitarian and social-economic sciences, 2017, vol. 11, S3, pp. 32-33.

[4] E. Katkova., et al., "The Rise of Russia-China International Cooperation in Higher Education", Proceedings of the 5th International Conference on Education, Language, Art and Inter-cultural Communication, ICELAIC 2018, Atlantis Press, 2018, vol. 289, pp. 10-13.

[5] N. S. Martyshenko, "Education system as the most important "soft power" tool of the border region", Azimuth of scientific researches: pedagogy and psychology, 2018, vol. 7, 2 (23), pp. 156-160.

[6] A. Gulimire and S.I. Titkova, "Russian language in China: traditions and perspectives", Scientific journal, Modern linguistic and methodologicaldidactic researches, 2018, 2 (38), pp. 68-78.

[7] G. Ya Grevtseva, "Cooperation of Russia and China in the sphere of education", Bulletin of the South-Ural state university, Series: Education, Pedagogical sciences, 2017, vol. 9, no. 2, pp. 43-52.

[8] A. D. Vasiliev, et al., "Development of foreign economic relations in Russia and China in the sphere of tourism", Scientific notes of the Crimean federal university named after V. I. Vernadsky, Economics and management, 2018, vol. 4 (70), 1, pp. 31-40.

[9] O. N. Konovalova and K. S. Chistaya, "Trade - investment cooperation of Russia and China: current situation, risks, problems and obstacles", Innovative economy and society, 2015, 2 (8), pp. 41-51.

[10] Y. V. Sitnikova and I. M. Karitskaya, "Russian-Chinese cooperation: five deterring factors, International scientific-research journal", 2016, 10-1 (52), pp. 38-40.

[11] N. S. Martyshenko, "'Soft power" mechanism as a tool to strengthen the cross-border cooperation", Region: Economics and Sociology, 2018, 4 (100), pp. 112-133.

[12] L. N. Smirnova, "Russia and China: 20 proposals for the economic, scientific and humanitarian partnership", Russian council on international affairs, Russia and China in Eurasian integration, 2015, pp. 319-336. 
[21] V. C. Keating and K. Kaczmarska, "Conservative soft power: Liberal soft power bias and the 'hidden' attraction of Russia", Journal of International Relations and Development, 2019, 22.1, pp. 1-27.

[13] E. P. Toporkova and L. Zhou, "To the research problem of perceiving the image of territories in Russia and China: the border aspect", Regional problems, 2015, vol. 18, 1, pp. 48-51.

[14] N. P. Kalashnikova and S. A. Zhasuzakov, "Greater Eurasia in context of the people's diplomacy", Society, 2019, 1 (12), pp. 92-98.

[15] L. G. McGann and G. James, "People's Republic of China: An Overview", Think Tanks, Foreign Policy and the Emerging Powers, Palgrave Macmillan, Cham, 2019, pp. 163-171.

[16] O. I. Bodrova, "The role of "people's diplomacy" in complex of the Chinese diplomatic tools", Bulletin of the Nizhny Novgorod university named after N. I. Lobachevsky, 2014, 5-1, pp. 64-68.

[17] M. F. Gatsko, "The role of "soft power" in ensuring the national security of modern Russia", Modern society and power, 2017, 3 (13), pp. 53-59.

[18] A. A. Kazantsev and L. Yu. Gusev, "Promotion of Russian "soft power" in Central Asia as the tool to develop the Eurasian economic integration", Management counseling, 2015, 11 (83), pp. 80-91.

[19] D. M. Cowba, "Main approaches to the study of "soft power" in the domestic political science", Discourse, Pi, 2017, vol. 14, 1, pp. 143 148.

[20] G. Narimani, et al., "Analysis of the Strategies and Tools to Consolidate and Expand China's Soft Power", 2018, pp. 165-202.
[22] N. G. Rogozhina, ""Soft power" in the policy of Chinese in countries of the South-Eastern Asia", South-Eastern Asia: actual development problem, 2017, 34, pp. 24-33.

[23] L. Song and Z. Qiqi, "A Model for the Belt and Road Initiative: China's Cultural Diplomacy Toward Central and Eastern European Countries", The Belt \& Road Initiative in the Global Arena, Palgrave Macmillan, Singapore, 2018, pp. 55-68.

[24] Z. Xi, "The Exercise and Role of China's Public Diplomacy in Europe within the Context of the "Belt and Road Initiative'", Stosunki Międzynarodowe, 2018, 54.2, pp. 143-162.

[25] E. F. Makarevich, "Soft power appeal and ways of its measurement", PolitBook, 2017, 1, pp. 30-48.

[26] A. I. Pakhomova, et al., "Methodology for assessing the sustainable social and development of cities taking into account the systems approach", Business Economics, 2017, vol. 52, 4-2, 589 p.

[27] E. O. Leontiev, "Chinese students in Far Eastern universities: stereotypes and real motivational attitudes (by example of Khabarovsk city)", Culture and science of the Far East, 2016, 2, pp. 36-40. 